\title{
Middle and Long-Term Impact of a Very Low-Carbohydrate Ketogenic Diet on Cardiometabolic Factors: A Multi-Center, Cross-Sectional, Clinical Study
}

\author{
Arrigo F. G. Cicero ${ }^{1} \cdot$ Maddalena Benelli $^{2} \cdot$ Marco Brancaleoni $^{3} \cdot$ Giuseppe Dainelli $^{3}$. \\ Desiré Merlini ${ }^{3} \cdot$ Raffaele Negri $^{3}$
}

Received: 26 February 2015/Accepted: 22 April 2015/Published online: 19 May 2015

(c) The Author(s) 2015. This article is published with open access at Springerlink.com

\begin{abstract}
Introduction Obesity is a constantly growing illness in developed countries and it is strictly related to cardiovascular $(\mathrm{CV})$ diseases, i.e. the main cause of mortality throughout industralised areas.

Aim to test the ability of trained general physician to safely and effectively prescribe a very-low carbohydrate ketogenic (VLCK) diet in clinical practice, with a specific attention to the effect of this approach on overweight related CV risk factors (anthropometric measures) blood pressure, lipid levels, glucose metabolism).

Methods The study has been carried out on a group of 377 patients scattered across Italy and monitored during 1 year. The proposed VLCK diet is a nutritional regimen characterized by low-fat and low- carbohydrates formulations and a protein content of $1.2 / 1.5 \mathrm{~g} / \mathrm{kg}$ of ideal body weight, followed by a period of slow re-insertion and alimentary re-education.

Results All the predetermined goals - namely safety, reduction of body weight and CV risk factors levels-have been reached with a significant reduction of body weight (from baseline to 4 weeks $(-7 \pm 5 \mathrm{~kg}, \mathrm{p}<0.001)$, from 4 to 12 weeks $(-5 \pm 3 \mathrm{~kg}, \mathrm{p}<0.001)$, no changes from
\end{abstract}

Lignaform Study Group: M. Benelli, M. Brancaleoni,

G. Dainelli, D. Merlini, R. Negri.

Arrigo F. G. Cicero

afgcicero@cardionet.it; arrigo.cicero@unibo.it

1 Medical and Surgical Sciences Department, Sant'OrsolaMalpighi University Hospital, University of Bologna, U.O. Medicina Interna Borghi-Via Albertoni, 15, Bologna, Italy

2 Santa Chiara Foundation, Lodi, Italy

3 National Public Health System, Rome, Italy
12 weeks to 12 months; waistline (from baseline to 4 weeks $(-7 \pm 4 \mathrm{~cm}, \mathrm{p}<0.001)$, from 4 to 12 weeks $(-5 \pm 7 \mathrm{~cm}$, $\mathrm{p}<0.001$ ), no changes from 12 weeks to 12 months; fatty mass (from baseline to 4 weeks $(-3.8 \pm 3.8 \%, \mathrm{p}<0.001)$, from 4 to 12 weeks $(-3.4 \pm 3.5 \%, \mathrm{p}<0.001)$, no changes from 12 weeks to 12 months; SBP from baseline to 3 months $(-10.5 \pm 6.4 \mathrm{mmHg}, \mathrm{p}<0.001)$, no further changes after 1 year of observation).

Conclusion the tested VLCD diet suggested by trained general physicians in the setting of clinical practice seems to be able to significantly improve on the middle-term a number of anthropometric, haemodynamic and laboratory with an overall good tolerability.

Keywords Ketogenic diet - General practice - Safety · Cardiovascular risk factors

\section{Introduction}

Overweight and obesity are pandemic conditions [1] associated to increased risk for type 2 diabetes, cardiovascular disease, cancer and all cause-mortality [2, 3], and a dramatic increase in public health expense to their management $[4,5]$. Mediterranean diet seems to be a model to preserve a good health, especially when followed for the life-span. However, the large amount of carbohydrate included in the modern Mediterranean diet could be not adequately metabolized in strongly sedentary people and favor body weight increase [6]. Several randomized clinical trials carried out in specialized medical setting have clearly shown that a short-term ketogenic diet could be useful to obtain a quick and relatively safe weight loss in selected patients [7, 8]. Moreover, the efficacy on body weight loss seems to be associated to a large number of 
positive metabolic changes, potentially useful to mitigate the features of the metabolic syndrome and contrasting the development of type 2 diabetes [9, 10]. In particular, a recent meta-analysis of randomized clinical trials, showed that ketogenic diets induce a long-term more significant improvement in body weight, diastolic blood pressure, triglycerides and HDL-cholesterol, when compared to low fat diets [11]. However, there are no many studies testing if this approach could be useful, feasible and safe also in a setting of general medicine [12]. This scientific question is of primary relevance, given the large prevalence of obesity in general population, that could not be managed in a hospital setting.

In this context, the aim of our study was to evaluate the efficacy and tolerability of a ketogenic diet suggested and monitored in the setting of general practice, in term of long and mid-term weight loss and modification of the main cardiovascular $(\mathrm{CV})$ disease risk factors.

\section{Methods}

General practitioners, well acquainted with VLCK diets methods selected by a senior physician already expert in the tested method, after a further specific training, have carried out this observational study.

The selected patients met the following inclusion requirements: they are aged between 30-69 years, have a BMI between $27-37 \mathrm{~kg} / \mathrm{m}^{2}$ and an abdominal circumference of $98 \mathrm{~cm}$ or more for men and $87 \mathrm{~cm}$ or more for women.

The exclusion from this study occurred in case of renal impairment (i.e. creatinine greater or equal to than $1.5 \mathrm{mg} /$ $\mathrm{dL}$ ), major depressive with eating disorders, serious hepatic impairment, insulin-dependent type 1 diabetes, oral anticoagulant treatment. Furthermore, patients with an ongoing anti-cancer treatment as well as pregnant or breast-feeding women were not taken into account.

The $21.1 \%$ of the subjects was affected by arterial hypertension, the $10 \%$ by impaired fasting glucose; the $6.4 \%$ by type 2 diabetes, the $3.2 \%$ was in secondary prevention for cardiovascular diseases. The $12.2 \%$ had pharmacologically compensated hypothyroidism.

After to have signed a specific informed consent form, eligible patients, at time zero, were subjected to a general medical examination and an evaluation of anthropometric and bio-humoral parameters.

Thirty-seven general practitioners identified, in three months' time, 377 eligible patients (M $21.2 \%$, W $78.8 \%$ ). Among them, 311 were selected, as they were the only participants to the first monitoring visit at 30 days. Sixtysix patients dropped-out for different reasons, but none of which of a clinical matter.
The next monitoring visits were planned first after 3 months and then after 12 months.

The enrolled patients have been subjected to VLCK diet (as implemented by Lignaform), a nutritional regimen is a VLCK diet, based on the use of high biological level protein formulation of milk/egg/legumes origin (peas and NO OGM soybeans), with a content of 15-18 g in proteins, 2-6 $\mathrm{g}$ in carbohydrates, $3 \mathrm{~g}$ in fats for a caloric intake of $100 \mathrm{kcal}$. Additionally, vegetables were allowed. The preparations were personally bought by patients.

Our method is articulated in different stages: in the first step we provide a protein intake of $1.2-1.5 \mathrm{~g} / \mathrm{kg}$ of ideal body weight [13], in association with low-glycemic index vegetables. Thus, it is a normal-protein regime compared to the ideal weight, but hyper-protein diet in relation to the others nutrients consumed.

Afterwards, the formulations are replaced by natural protein foods and the diet is gradually completed with other aliments on the base of glycemic index following a multiphasic scheme.

Firstly, patients were exclusively treated with formulations and vegetables (stage 1). Then, only one formulation was replaced by a protein aliment (meat, fish, eggs) and vegetables (stage 2). Immediately after, another formulation was substituted with another protein food (conclusion of stage 2). Eventually, patients inserted, in sequential, fruit, dairy products, cereals and legumes (stages 3-4-5-6). The duration of each stage is proportional to weight loss during the ketogenic periods. The last stage (stage 7) consisted in a re-education to the Mediterranean diet based on patient's expenditure of energy.

However, from the very beginning an integration of calcium, magnesium, potassium, omega 3 fatty acids $(500 \mathrm{mg})$ and olive oil is necessary.

The following variables have been measured with standardized methods or calculated at the baseline, at the monitoring visit at 30 days, then after 3 and 12 months: height, weight, body mass index (BMI), waist circumference (WC), index of central obesity $(\mathrm{ICO}=$ ratio of waist circumference and height), impedentiometrically estimated fat mass, systolic (SBP), diastolic (DBP) and pulse pressure (PP), thyroid stimulating hormone (TSH), fasting plasma glucose (FPG), glycated haemoglobin (HbA1c), total cholesterol (TC), LDL cholesterol (LDL-C), HDL cholesterol (HDL-C), triglycerides, liver transaminases, gammaglutamyl transferase (gGT), creatinine, estimated glomerular filtration rate (eGFR, CKD-EPI formula), microalbuminuria, uric acid (SUA), serum potassium, sodium, magnesium and calcium.

A complete descriptive analysis was carried out for continuous and categorical parameters. Categorical parameters were compared by the chi-square test followed by the Fisher exact test. Normally distributed parameters were 
compared with ANOVA for paired and unpaired samples, followed by the Student t-test, while not-normally distributed parameters with Kruskal-Wallys analysis of variance followed by Mann-Whitney $U$ test. The predictor of a more significant weight loss were identified by the application of a logistic regression test. A significance level of 0.05 has been chosen for all tests. All the analyses were carried out with the help of SPSS 21.0, version for Windows.

\section{Results}

The main characteristics of the enrolled patients are resumed in Table 1. Throughout the study, $82.5 \%$ of the patients involved in the study, completed the first 4 week period, $71.1 \%$ the first 12 -week period, $52 \%$ continued the protocol until 12 months.

All the measured anthropometric variables exhibited a similar trend.

Body weight significantly improved from baseline to 4 weeks $(-7 \pm 5 \mathrm{~kg}, \mathrm{p}<0.001)$, from 4 to 12 weeks $(-5 \pm 3 \mathrm{~kg}, \mathrm{p}<0.001)$, while no changes were observed from 12 weeks to 12 months $(-1 \pm 2 \mathrm{~kg}$, $\mathrm{p}=0.06$ ). Therefore, after 1 year the subjects experienced a mean total body weight loss of $14 \pm 10 \mathrm{~kg}$.

The BMI significantly improved from baseline to 4 weeks $\left(-3 \pm 2 \mathrm{~kg} / \mathrm{m}^{2}, \mathrm{p}<0.001\right)$, from 4 to 12 weeks $\left(-2 \pm 2 \mathrm{~kg} / \mathrm{m}^{2}, \mathrm{p}<0.001\right)$, while no changes were observed from 12 weeks to 12 months $\left(-0.2 \pm 0.9 \mathrm{~kg} / \mathrm{m}^{2}\right.$, $\mathrm{p}=0.08$ ). Therefore, after 1 year the subjects experienced a mean total body weight loss of $5 \pm 3 \mathrm{~kg} / \mathrm{m}^{2}$.

The WC significantly improved from baseline to 4 weeks $(-7 \pm 4 \mathrm{~cm}, \mathrm{p}<0.001)$, from 4 to 12 weeks $(-5 \pm 7 \mathrm{~cm}$, $\mathrm{p}<0.001$ ), while no significant changes were observed from 12 weeks to 12 months $(-0.2 \pm 1.1 \mathrm{~cm}, \mathrm{p}=0.68)$, so after 1 year the subjects experienced a mean total body weight loss of $13 \pm 7 \mathrm{~cm}$.

The ICO improved from baseline to 4 weeks $(-0.04 \pm 0.02$, $\mathrm{p}<0.001)$, from 4 to 12 weeks $(-0.03 \pm 0.04, \mathrm{p}<0.001)$, while no significant changes were observed from 12 weeks to 12 months $(-0.01 \pm 0.04, \mathrm{p}=0.64)$. Therefore after 1 year the subjects experienced a mean total body weight loss of $0.8 \pm 0.4$.

The estimated percentage of body fat significantly improved from baseline to 4 weeks $(-3.8 \pm 3.8 \%$, $\mathrm{p}<0.001)$, from 4 to 12 weeks $\quad(-3.4 \pm 3.5 \%$, $\mathrm{p}<0.001$ ), while no significant changes were observed from 12 weeks to 12 months $(-0.2 \pm 1.1 \mathrm{~cm}, \mathrm{p}=0.89)$, therefore after 1 year the subjects experienced a mean total body weight loss of $8.1 \pm 5.9 \%$ (Fig. 1).

Regarding the haemodynamic parameters, SBP significantly improved from baseline to 3 months $(-10.5 \pm 6.4 \mathrm{mmHg}$,
Table 1 Main anthropometric, haemodynamic and laboratory characteristics of the enrolled subjects at the baseline (value compared between genders)

\begin{tabular}{|c|c|c|}
\hline Variable & Men & Women \\
\hline Age (years) & $48.3 \pm 10.9 *$ & $45.6 \pm 9.9$ \\
\hline Body weight $(\mathrm{kg})$ & $97.5 \pm 10.8^{*}$ & $81.9 \pm 10.4$ \\
\hline Body mass index $\left(\mathrm{kg} / \mathrm{m}^{2}\right)$ & $32.1 \pm 2.8^{*}$ & $31.2 \pm 3.1$ \\
\hline Waist circumference $(\mathrm{cm})$ & $108.3 \pm 9.6^{*}$ & $99.6 \pm 10.0$ \\
\hline Index of central obesity & $0.62 \pm 0.05$ & $0.61 \pm 0.06$ \\
\hline Fat mass $(\%)$ & $41.4 \pm 16.3^{*}$ & $37.3 \pm 15.9$ \\
\hline Systolic blood pressure $(\mathrm{mmHg})$ & $132.5 \pm 14.2 *$ & $128.0 \pm 15.1$ \\
\hline Dyastolic blood pressure $(\mathrm{mmHg})$ & $78.9 \pm 7.7^{*}$ & $75.9 \pm 11.3$ \\
\hline Pulse pressure (mmHg) & $53.5 \pm 12.8$ & $52.1 \pm 14.6$ \\
\hline TSH (uUI/mL) & $2.1 \pm 1.3$ & $2.6 \pm 2.5$ \\
\hline Fasting plasma glucose (mg/dL) & $104.6 \pm 21.8^{*}$ & $95.7 \pm 27.0$ \\
\hline Glycated haemoglobin (\%) & $5.5 \pm 0.9$ & $5.5 \pm 0.8$ \\
\hline Total cholesterol (mg/dL) & $215.6 \pm 35.4$ & $211.8 \pm 39.3$ \\
\hline HDL cholesterol (mg/dL) & $45.2 \pm 10.5^{*}$ & $56.3 \pm 14.9$ \\
\hline LDL cholesterol (mg/dL) & $138.7 \pm 31.7$ & $132.9 \pm 36.1$ \\
\hline Triglycerides (mg/dl) & $158.9 \pm 75.3 *$ & $117.0 \pm 67.9$ \\
\hline AST (U/L) & $25.0 \pm 10.9^{*}$ & $21.2 \pm 7.5$ \\
\hline ALT (U/L) & $33.3 \pm 19.5^{*}$ & $23.4 \pm 10.8$ \\
\hline Gamma glutamyl transferase (U/L) & $32.6 \pm 16.9^{*}$ & $23.2 \pm 17.4$ \\
\hline Creatinine $(\mathrm{mg} / \mathrm{dL})$ & $0.93 \pm 0.15^{*}$ & $0.80 \pm 0.15$ \\
\hline Serum uric acid (mg/dL) & $5.6 \pm 1.2^{*}$ & $4.5 \pm 1.2$ \\
\hline Microalbuminuria (mg/L) & $10.3 \pm 7.2^{*}$ & $8.9 \pm 9.3$ \\
\hline Serum potassium $(\mathrm{mEq} / \mathrm{L})$ & $4.9 \pm 1.8$ & $4.3 \pm 1.3$ \\
\hline Serum sodium $(\mathrm{mEq} / \mathrm{L})$ & $139.4 \pm 3.8$ & $139.2 \pm 3.1$ \\
\hline Serum magnesium (mg/dL) & $2.0 \pm 0.6$ & $1.9 \pm 0.5$ \\
\hline Serum calcium (mg/dL) & $8.9 \pm 1.2$ & $8.9 \pm 1.2$ \\
\hline
\end{tabular}

$* \mathrm{p}<0,05$, men vs. women

$\mathrm{p}<0.001$ ) but no changes were observed after 1 year of observation. A similar trend, has been noticed for DBP $(-2.2 \pm 3.1 \mathrm{mmHg}, \mathrm{p}<0.001)$ and $\mathrm{PP}(-8.3 \pm 6.2 \mathrm{mmHg}$, $\mathrm{p}<0.001)$.

FPG significantly improved from baseline to 4 weeks $(-8.7 \pm 15.3 \mathrm{mg} / \mathrm{dL}, \mathrm{p}<0.001)$ and no change were observed after 1 year of monitor. Similarly, HbA1c improved from baseline to 3 months $(-0.3 \pm 0.7 \mathrm{mg} / \mathrm{dL}, \mathrm{p}<0.001)$ and held steady after 1 year of observation.

About lipid parameters, LDL-C significantly improved from baseline to 3 months $(-19.5 \pm 16.9 \mathrm{mg} / \mathrm{dL}, \mathrm{p}<0.001)$ and we noticed no change after 1 year of observation. A similar trend has been observed for TG $(-23.4 \pm 30.2 \mathrm{mg} /$ $\mathrm{dL}, \mathrm{p}<0.001$ ), while HDL-C improved from baseline to 4 weeks $(+1.8 \pm 5.6 \mathrm{mg} / \mathrm{dL}, \mathrm{p}=0.038)$, and even more after 12 months $(+3.5 \pm 3.3 \mathrm{mg} / \mathrm{dL}, \mathrm{p}<0.001)$.

As regards the liver parameters, AST significantly improved from 1 to 3 months $(-2.2 \pm 3.2 \mathrm{U} / \mathrm{L}, \mathrm{p}<0.001)$, and no other changes were marked after 1 year of observation. A 

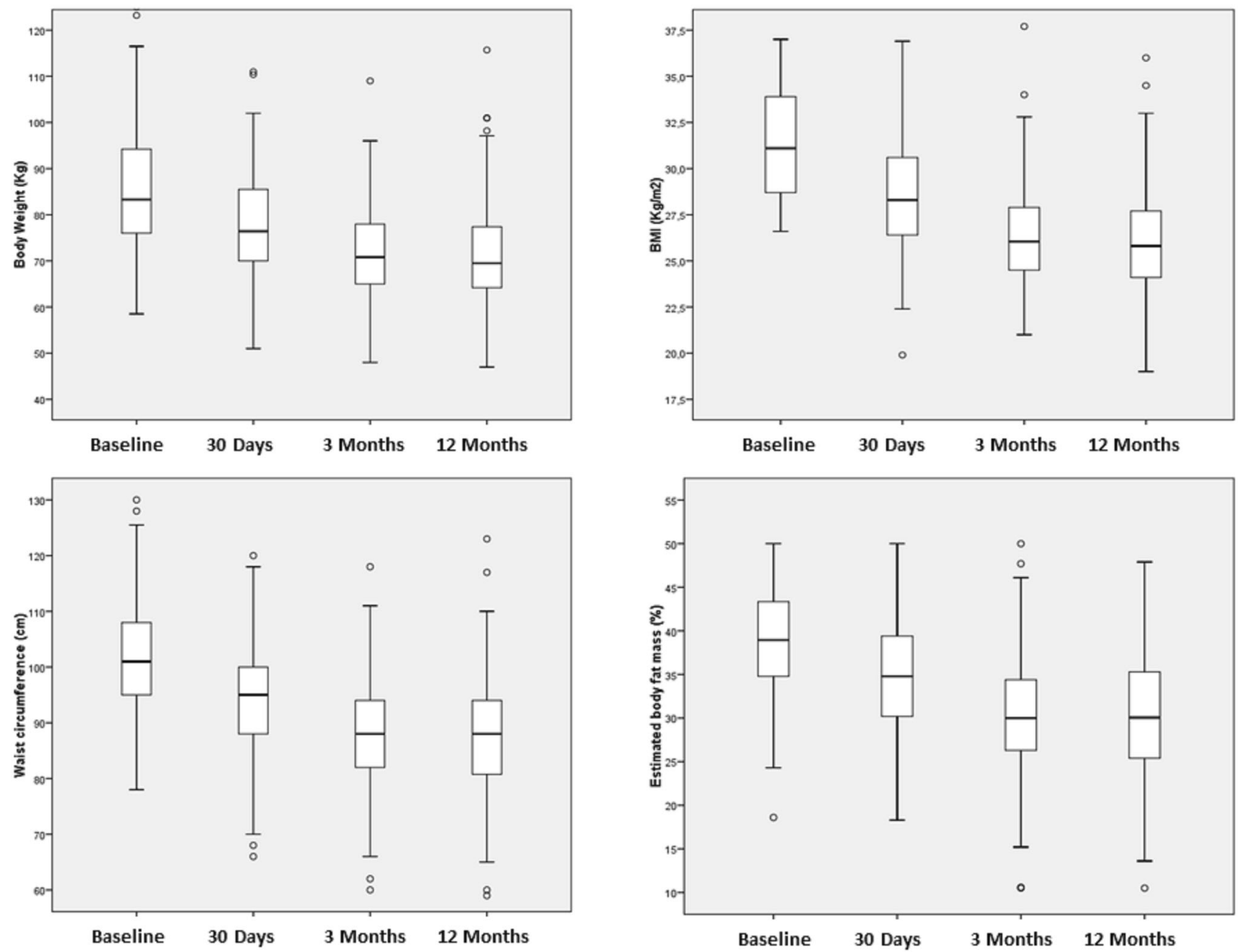

Fig. 1 Body weight, BMI, waist circumference, and estimated body fat mass changes during the different study phases

similar trend has been observed for ALT $(-3.1 \pm 5.3 \mathrm{U} / \mathrm{L}$, $\mathrm{p}<0.001)$, while gamma-GT improved from baseline to 4 weeks $(-4.1 \pm 5.2 \mathrm{mg} / \mathrm{dL}, \mathrm{p}<0.001)$, with no other significant changes after 1 year of observation.

With reference to renal parameters, estimated glomerular filtration rate (eGFR), creatinine level and microalbuminuria were not significantly modified during the observation period, while uricemia mildly but significantly improved from the 3rd month to the end of the study $(-0.4 \pm 1.5 \mathrm{mg} / \mathrm{dL}, \mathrm{p}=0.048)$.

No significant change has been observed as regards serum level of potassium, sodium and magnesium. However calcemia mildly but significantly decreased from baseline to 30 days $(-0.35 \pm 0.82 \mathrm{mg} / \mathrm{dL}, \mathrm{p}=0.001)$, while it improved in the following period from 30 to 90 days $(+0.21 \pm 0.71 \mathrm{mg} / \mathrm{dL}, \mathrm{p}=0.017)$.

No changes have been observed in the standard urinalysis.

The short-term body weight loss was quicker in men than in women $(\mathrm{p}<0.05)$, greater in those subjects experiencing a ketonuria in the first period of diet ( $\mathrm{p}<0.001$ ), and was directly related to the baseline body weight (RR 1.10, $95 \%$ CI 1.04-1.16, p < 0.001), and inversely to patient age ( $\mathrm{RR}-0.20,95 \% \mathrm{CI}-0.27$ to -0.15 , $\mathrm{p}<0.001$ ), while the long term body weight loss was greater in those subjects experiencing a ketonuria in the first period of diet $(\mathrm{p}<0.05)$, and was directly related to the baseline body weight (RR 1.26, $95 \%$ CI 1.27-1.18, $\mathrm{p}<0.001$ ) and body fat mass (RR 1.17, $95 \% \mathrm{CI}$ $1.01-1.33, \mathrm{p}=0.033$ ).

\section{Discussion}

The international guidelines for cardiovascular disease prevention suggest, as a first step, the optimization of dietary habits in order to improve the cardiovascular disease risk [14, 15]. In our study, carried out in the setting of general practice, we observed that a short-term ketogenic diet is able to improve both on the short and long-term a 
large number of anthropometric, haemodynamic and metabolic parameters related to the cardiovascular disease risk. In particular we examined a significant improvement in body weight, BMI, WC, ICO, estimated body fat, SBP, DBP, PP, FPG, HbA1c, LDL-C, TG and HDL-C levels, that tend to remain stable after 1 year from the end of the short ketogenic period. The mild improvement of uricemia observed in the trial could also have some relevant prognostic implication [16].

These changes have not been associated to any clinically relevant adverse event.

Our results, in terms of body weight and lipid control improvement, are in good agreement with previous shortterm randomized clinical trials comparing the effect of high protein diets to standard protein nutritional regimes [17]. A more recent meta-analysis of 17 randomized clinical trials involving 1141 obese patients confirmed our observation, showing that low-carb/high protein diets are also associated to a significant improvement of systolic and diastolic BP, basal glycaemia and HbA1c [18]. Beyond the low intake of carbohydrate, low-fat diets induce improvement in basal insulinemia depending on protein content in the diet itself, as high protein diets are associated to improved insulinemia, and consequently improved glucose metabolism [19]. The long-term positive effects on body weight and other metabolic parameters observed in our study could be explained by the maintenance of a low-glycaemic index diet after the ketogenic hyperproteic period of the tested method [20]. Nevertheless, our study has a few relevant limitations worth to be considered.

First, it is not a randomized but an observational clinical trial. Thus, one can say that observed effects are related to the reduction of energy intake per se rather than the tested dietary method [21].

Moreover, one can argue that the baseline characteristics of the enrolled patients were not homogenous as well as different physician ability to discuss the methods could have influenced the efficacy of the method itself. This can be understood looking at the goal we wanted to reach, that was to mimic real patients that a general practitioner usually cope with.

However, at the best of our knowledge, this is the first report one can find in the literature of the efficacy and tolerability of a short-term ketogenic intervention on overweight and obese patients outside highly specialized centres, with a relatively long follow-up after intervention end [22].

\section{Conclusion}

With the limitation of an observational study, in our experience a short-term ketogenic diet managed in the setting of general practice seemed to be able to improve a large number of anthropometric, haemodynamic and metabolic parameters related to the cardiovascular disease risk, with improvements maintained also on the long-term [23, 24]. Further randomized clinical trials are expect to confirm these positive results.

Acknowledgments Authors gratefully acknowledge Therascience nutritional laboratory for developing Lignaform method. We feel indebted to all of the physicians that participated in this study by collecting data as well as taking care of the patients who took part in this work. We also thank Alessandra Conte for reading manuscript and useful suggestions.

Open Access This article is distributed under the terms of the Creative Commons Attribution-NonCommercial 4.0 International License (http://creativecommons.org/licenses/by-nc/4.0/), which permits any noncommercial use, distribution, and reproduction in any medium, provided you give appropriate credit to the original author(s) and the source, provide a link to the Creative Commons license, and indicate if changes were made.

\section{References}

1. Ng M, Fleming T, Robinson M, Thomson B, Graetz N, Margono $\mathrm{C}$, et al. Global, regional, and national prevalence of overweight and obesity in children and adults during 1980-2013: a systematic analysis for the Global Burden of Disease Study 2013. Lancet. 2014;384:766-81.

2. Olshansky SJ, Passaro DJ, Hershow RC, Layden J, Carnes BA, Brody J, Hayflick L, Butler RN, Allison DB, Ludwig DS. A potential decline in life expectancy in the United States in the 21st century. N Engl J Med. 2005;352:1138-45.

3. Koh-Banerjee P, Wang Y, Hu FB, Spiegelman D, Willett WC, Rimm EB. Changes in body weight and body fat distribution as risk factors for clinical diabetes in US men. Am J Epidemiol. 2004;159:1150-9.

4. Cicero AF, Rosticci M, D'Addato S, Baronio C, Grossi G, Grandi E, Borghi C. Population health needs assessment and healthcare services use in a 3 years follow-up on administrative and clinical data: results from the Brisighella Heart Study. High Blood Press Cardiovasc Prev. 2014;21(1):45-51.

5. Finkelstein EA, Ruhm CJ, Kosa KM. Economic causes and consequences of obesity. Annu Rev Public Health. 2005;26:239-57.

6. Bellisle F. Infrequently asked questions about the Mediterranean diet. Public Health Nutr. 2009;12:1644-7.

7. Johnstone AM, Horgan GW, Murison SD, Bremner DM, Lobley GE. Effects of a high-protein ketogenic diet on hunger, appetite, and weight loss in obese men feeding ad libitum. Am J Clin Nutr. 2008;87:44-55.

8. Paoli A, Bianco A, Grimaldi KA, Lodi A, Bosco G. Long term successful weight loss with a combination biphasic ketogenic Mediterranean diet and Mediterranean diet maintenance protocol. Nutrients. 2013;5:5205-17.

9. Schugar RC, Crawford PA. Low-carbohydrate ketogenic diets, glucose homeostasis, and nonalcoholic fatty liver disease. Curr Opin Clin Nutr Metab Care. 2012;15:374-80.

10. Paoli A, Rubini A, Volek JS, Grimaldi KA. Beyond weight loss: a review of the therapeutic uses of very-low-carbohydrate (ketogenic) diets. Eur J Clin Nutr. 2013;67:789-96.

11. Bueno NB, de Melo IS, de Oliveira SL, da Rocha Ataide T. Verylow-carbohydrate ketogenic diet v. low-fat diet for long-term 
weight loss: a meta-analysis of randomised controlled trials. Br J Nutr. 2013;110:1178-87.

12. Paoli A. Ketogenic diet for obesity: friend or foe? Int J Environ Res Public Health. 2014;11:2092-107.

13. Hoffer LJ, Bistrian BR, Young VR, Blackburn GL, Matthews DE. Metabolic effects of very low calorie weight reduction diets. J Clin Invest. 1984;73:750-8.

14. The Task Force for the management of dyslipidaemias of the European Society of Cardiology (ESC) and the European Atherosclerosis Society (EAS). ESC/EAS Guidelines for the management of dyslipidaemias. Eur Heart J. 2011;32:1769-818.

15. The American College of Cardiology, American Heart Association Task force on Practice Guidelines and the Obesity society. AHA/ACC/TOS Guideline for the management of overweight and obesity in adults. $\mathrm{J}$ Am Coll Cardiol. 2013;2014(63):2985-3023.

16. Cicero AF, Rosticci M, Reggi A, Derosa G, Parini A, Grandi E, D'Addato S, Borghi C. Relationship between serum uric acid and electrocardiographic alterations in a large sample of general population: data from the Brisighella Heart Study. High Blood Press Cardiovasc Prev. 2014 (Epub ahead of print) PubMed PMID:25512187.

17. Clifton PM, Bastiaans K, Keogh JB. High protein diets decrease total and abdominal fat and improve CVD risk profile in overweight and obese men and women with elevated triacylglycerol. Nutr Metab Cardiovasc Dis. 2009;19:548-54.
18. Santos FL, Esteves SS, da Costa Pereira A, Yancy WS Jr, Nunes JP. Systematic review and meta-analysis of clinical trials of the effects of low carbohydrate diets on cardiovascular risk factors. Obes Rev. 2012;13:1048-66.

19. Schwingshackl L, Hoffmann G. Long-term effects of low-fat diets either low or high in protein on cardiovascular and metabolic risk factors: a systematic review and meta-analysis. Nutr J. 2013;12:48.

20. Schwingshackl L, Hoffmann G. Long-term effects of low glycemic index/load vs. high glycemic index/load diets on parameters of obesity and obesity-associated risks: a systematic review and meta-analysis. Nutr Metab Cardiovasc Dis. 2013;23:699-706.

21. Moreno B, Bellido D, Sajoux I, Goday A, Saavedra D, Crujeiras $\mathrm{AB}$, Casanueva FF. Comparison of a very low-calorie-ketogenic diet with a standard low-caloriediet in the treatment of obesity. Endocrine. 2014;47:793-805.

22. Cotter DG, Schugar RC, Crawford PA. Ketone body metabolism and cardiovascular disease. Am J Physiol Heart Circ Physiol. 2013;304:H1060-76.

23. Bravata DM, Sanders L, Huang J, Krumholz HM, Olkin I, Gardner CD, Bravata DM. Efficacy and safety of low-carbohydrate diets: a systematic review. JAMA. 2003;289:1837-50.

24. Foster GD, Wyatt HR, Hill JO, McGuckin BG, Brill C, Mohammed BS, Szapary PO, Rader DJ, Edman JS, Klein S. A randomized trial of a low-carbohydrate diet for obesity. N Engl J Med. 2003;348:2082-90. 